\title{
Building density derived from aerial photo mapping for physical vulnerability reduction in earthquake hazard zone of Sengon village, Central Java
}

\author{
Djati Mardiatno1, Denni Susanto², Tiara Handayani ${ }^{3}$, Lies Rahayu W. Faida ${ }^{4}$, \\ Bevaola Kusumasari ${ }^{5}$
}

1,2,3,4,5 Faculty of Geography, Universitas Gadjah Mada, Faculty of Forestry, Universitas Gadjah Mada, Faculty of Social and Political Science, Universitas Gadjah Mada, Center for Natural Disasters Studies, Universitas Gadjah Mada djati.mardiatno@ugm.ac.id

Article History

accepted 31/08/2020

approved 22/09/2020

published $28 / 10 / 2020$

\begin{abstract}
Building density is an important parameter for earthquake vulnerability mapping. Sengon village, Klaten, Central Java, which located in active fault zone of Opak is still lack of strategies for risk reduction in relation to physical vulnerability, especially to building density. The aims of this research is to 1) calculate the building density, 2) identify the relation of building density and population number, and 3) propose vulnerability reduction planning for physical characteristic. Building density calculate from aerial photo mapping. This method is robust and effective, resulting data of building density that Dusun Belan is the densest. In Sengon village, building density and population has positive correlation. Most of buildings is inhabited by 1-2 households. Sengon village can adapt several strategies for vulnerability physical reduction, i.e. a) design a strong and eco-friendly earthquake building especially for building inhabited by $>3$ $H \mathrm{H}, \mathrm{b})$ provide an open space and evacuation route in denser building area.
\end{abstract}

Keywords: earthquake, vulnerability, resilient village

\begin{abstract}
Abstrak
Kepadatan bangunan menjadi salah satu parameter penting dalam analisis kerentanan fisik untuk ancaman gempa bumi. Desa Sengon, Jawa Tengah yang terletak di kawasan bahaya gempa bumi jalur Sesar Opak memiliki permukiman yang mengelompok. Tujuan dari penelitian ini adalah 1) menghitung kepadatan bangunan di Desa Sengon, 2) menganalis keterkaitan kepadatan bangunan dengan jumlah penduduk, dan 3) menentukan rencana pengurangan kerentanan fisik di Desa Sengon sebagai Destana. Kepadatan bangunan dihitung melalui pemotretan udara menggunakan drone. Kepadatan bangunan dan jumlah penduduk di Desa Sengon memiliki korelasi yang positif. Rata-rata per bangunan dihuni oleh 1-2 kepala keluarga. Untuk mengurangi kerentanan fisik yang berkaitan dengan kepadatan bangunan, Desa Sengon dapat melakukan beberapa program seperti a) mendesain rumah ramah dan tahan gempa bumi khususnya bagi bangunan berpenghuni $>3 \mathrm{KK}$, dan b) menyediakan ruang terbuka dan jalur evakuasi pada wilayah yang padat bangunan.
\end{abstract}

Kata kunci: gempa bumi, kerentanan, desa tangguh bencana

Social, Humanities, and Education Studies (SHEs): Conference Series https://jurnal.uns.ac.id/shes

p-ISSN 2620-9284 e-ISSN 2620-9292 


\section{PENDAHULUAN}

Gempa bumi terjadi akibat adanya getaran yang disebabkan oleh tenaga endogen atau tenaga yang berasal dari dalam bumi (Bayong, 2006). Indonesia termasuk negara yang memiliki tingkat kegempaan yang tinggi di dunia, karena terletak pada tiga pertemuan lempeng tektonik dan sebagai jalur cincin gunung api sehingga berisiko terhadap gempa tektonik mapun vulkanik. Risiko tersebut tidak bisa dihindari, tetapi dapat ditanggulangi dan dikurangi dampaknya melalui langkah nyata pembangunan yang tepat (PSBA, 2008). Darah Istimewa Yogyakata dan Jawa Tengah pada tahun 2006 penah mengalami gempa bumi dengan kekuatan 5,9 SR yang sampai sekarang masih meninggalkan trauma pada sebagain warga. Salah satu desa yang terdampak gempa 2006 adalah Desa Sengon, Kabupaten Klaten Provinsi Jawa Tengah. Hampir seluruh wilayah desa mengalami kerusakan parah bahkan menelan banyak korban jiwa. Sampai saat ini masih belum ada dokumen pengurangan risiko bencana di wilayah tersebut. Selain itu pembangunan rumah di Desa Sengon semakin padat sehingga dapat meningkatkan kerentanan secara fisik. Informasi kepadatan bangunan di Desa Sengon menjadi salah satu informasi yang penting untuk langkah mitigasi bencana karena semakin padat suatu bangunan mengindikasikan tingginya kerentanan secara fisik (Ningthoujam dan Radhikesh, 2018).

Desa Sengon memiliki luas desa 233 ha yang terbagi ke dalam empat tipe penggunaan lahan yaitu tanah sawah (165 ha), tanah kering (55 ha), fasilitas umum (7,8 ha), dan fasilitas sosial (6 ha) (Desa Sengon, 2018). Desa Sengon memiliki jumlah penduduk 4.138 yang terbagi kedalam 16 dusun. Sebagain penduduk Desa Sengon berada pada usia produktif. Desa Sengon memiliki penggunaan lahan sawah lebih dari $60 \%$ dari total wilayah Desa Sengon, sehingga menjadi keuntungan sendiri dalam hal evakuasi karena memiliki lahan terbuka yang cukup banyak. Jalur evakuasi di Desa Sengon teah diiniasi dan dilengkapi dengan beberapa titik kumpul sementara dan titik kumpul akhir (Mardiatno dkk., 2020). Persebaan permukiman yang mengelompok dan sebagian menyebar menjadi salah satu tantangan dalam proses evakuasi atau tanggap darurat bencana. Adanya informasi tentang kepadatan bangunan akan sangat membantu dalam penyusunan perencanan mitigasi di Desa Sengon. Foto udara dari penelitian sebelumnya (Mardiatno dkk., 2020) akan sangat membantu dalam mengidentifikasi kepadatan bangunan di Desa Sengon. Analsis bangunan pada ancaman gempa bumi juga sangat penting dilakukan karena sebagian besar kerugian ekonomi berasal dari keterpaparan bangunan. Sejarah gempa tahun 2006 membuktikan bahwa kerugian bangunan paling besar disebabkan oleh bangunan yang berstruktur batu bata dan semen, sedangkan yang paling rentan adalah bagunan yang terbuat dari kayu (Aulady dan Fujimi, 2019). Penelitian ini bertujuan untuk melalukan analisis pengurangan kerentanan fisik berdasarkan informasi kepadatan bangunan dari hasil pemotretan foto udara.

\section{METODE}

Perhitungan kepadatan bangunan dilakukan dengan memanfaatkan data foto udara dari penelitian sebelumnya (Mardiatno dkk., 2020). Foto udata tersebut diambil menggunakan drone quadcopter pada semua dusun di Desa Sengon. Contoh hasil foto udaa dapat dilihat pada Gambar 1. Penentuan jumlah bangunan diawali dengan digitasi bangunan per-atap. Kepadatan bangunan dihitung dengan membagi jumlah bangunan persatuan luas (ha). Untuk lebih memudahkan skala analisis, maka nilai kepadatan bangunan dihitung pada setiap dusun, sehingga menghasilkan data 16 nilai kepadatan bangunan dengan satuan bangunan/ha. Nilai tersebut kemudian dikorelasikan dengan jumlah penduduk untuk mengetahui karakteristik persebaran hunian dengan asumsi semakin besar jumlah penduduk, maka kepadatan bangunan semakin tinggi. Pada penelitian ini karakterisitik bangunan yang dianalisis adalah kepadatannya saja, jenis bangunan diabaikan karena termasuk variabel yang tidak 
berdampak langsung pada proses pemulihan. namun demikian, variable bangunan tersebut dapat dikorelasikan dengan kondisi penduduk (jumlah atau kepadatan) karena dapat bepengaruh pada kemampuan melenting (resilience) suatu masyarakat (Irajifar dkk., 2016)
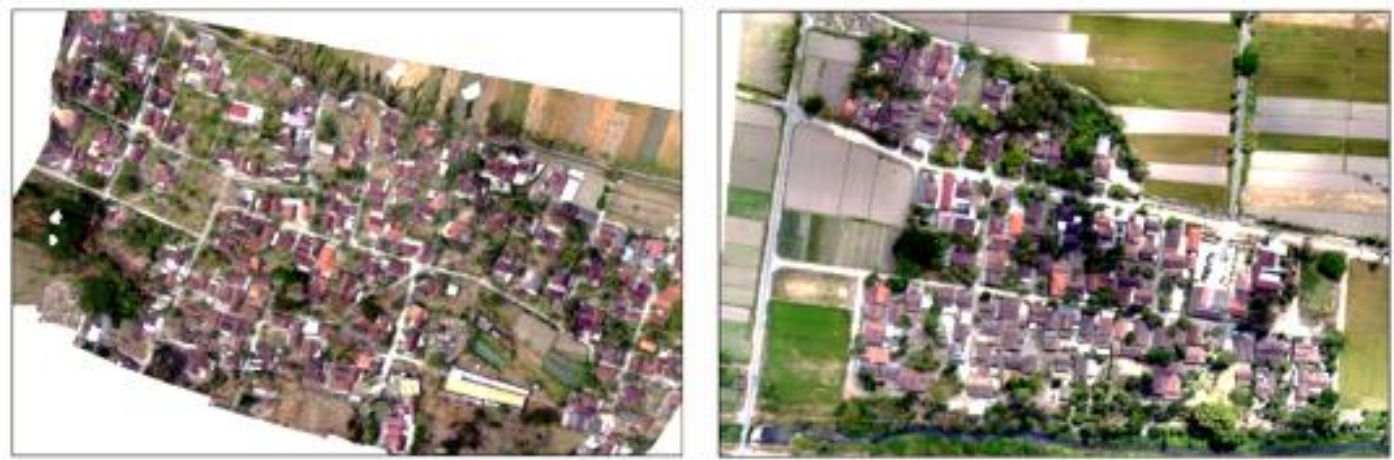

Gambar 1. Contoh hasil foto di Dusun Mangunjayan dan Belan Wetan, Desa Sengon

HASIL DAN PEMBAHASAN

Desa Sengon termasuk desa yang memiliki jenis permukiman yang mengelompok, namun terpisah oleh lahan sawah. Hal ini dapat telihat dari hasil digitasi foto udara persebaran bangunan yang ada di Desa Sengon (Gambar 2). Pada gambar tesebut terlihat bahwa bangunan mengelompok pada klaster dusun. Persebaan bangunan pada Gambar 2 juga mempelihatkan bahwa ada dusun yang relatif padat dan ada yang relatif renggang.

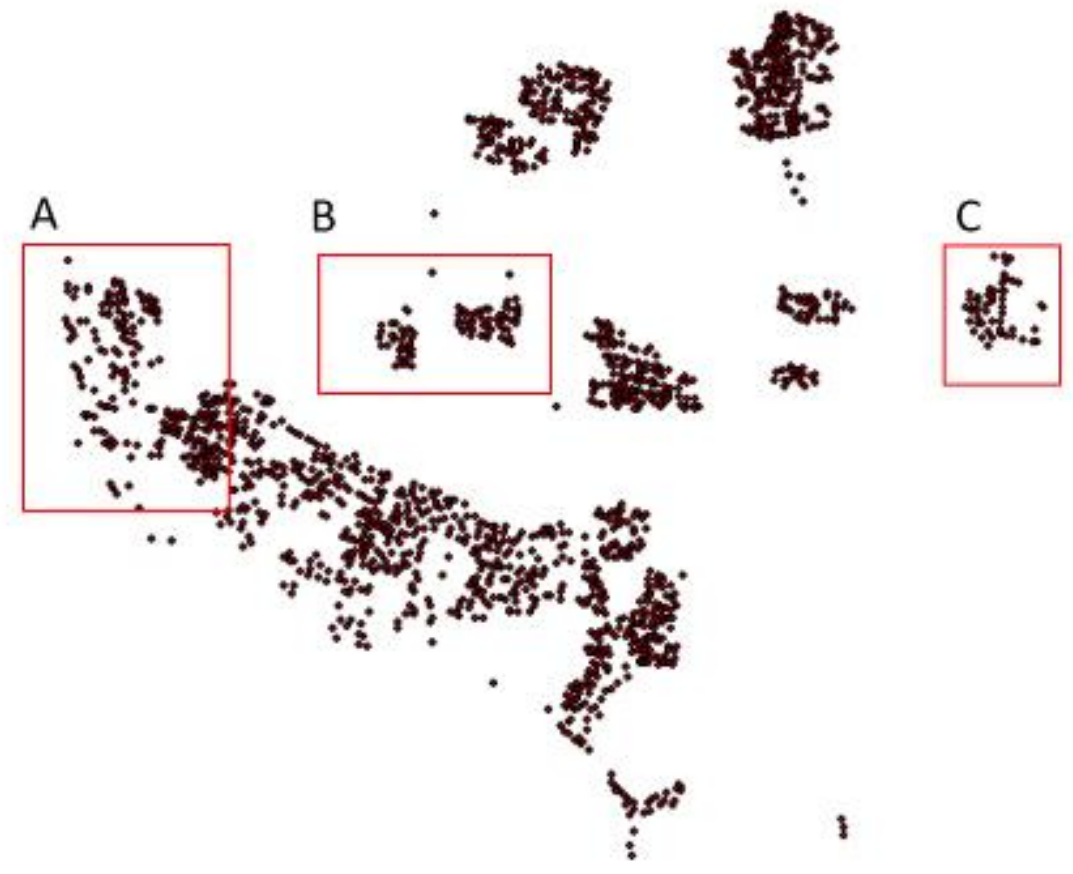

Gambar 2. Persebaran titik bangunan (A) kepadatan sedang, (B) tinggi, (C) rendah

Hasil persebaran titik bangunan tersebut menunjukkan bahwa terdapat 4 dusun yang memiliki tingkat kepadatan tinggi yaitu Dusun Cabakan, Sengon, Sumberejo, dan Belan seperti yang terlihat pada Gambar 3. Dusun Cabakan dan Sengon terletak di sisi utara Desa Sengon, sementara Dusun Belan di bagian tengah, dan Dusun Sambirejo di sisi selatan. Dusun Cabakan dan Dusun Belan merupakan dusun yang memiliki tingkat kepadatan bangunan paling padat dibandingkan dusun lainnya di Desa 
Sengon. Berdasarkan peta tersebut, juga digambarkan jalur evakuasi dengan garis merah. Jalur evakuasi ini digunakan untuk memudahkan proses evakuasi menuju titik kumpul saat kejadian bencana. Di Desa Sengon sendiri terdapat dua titik kumpul, yaitu titik kumpul sekunder dan titik kumpul primer (Mardiatno, 2020).

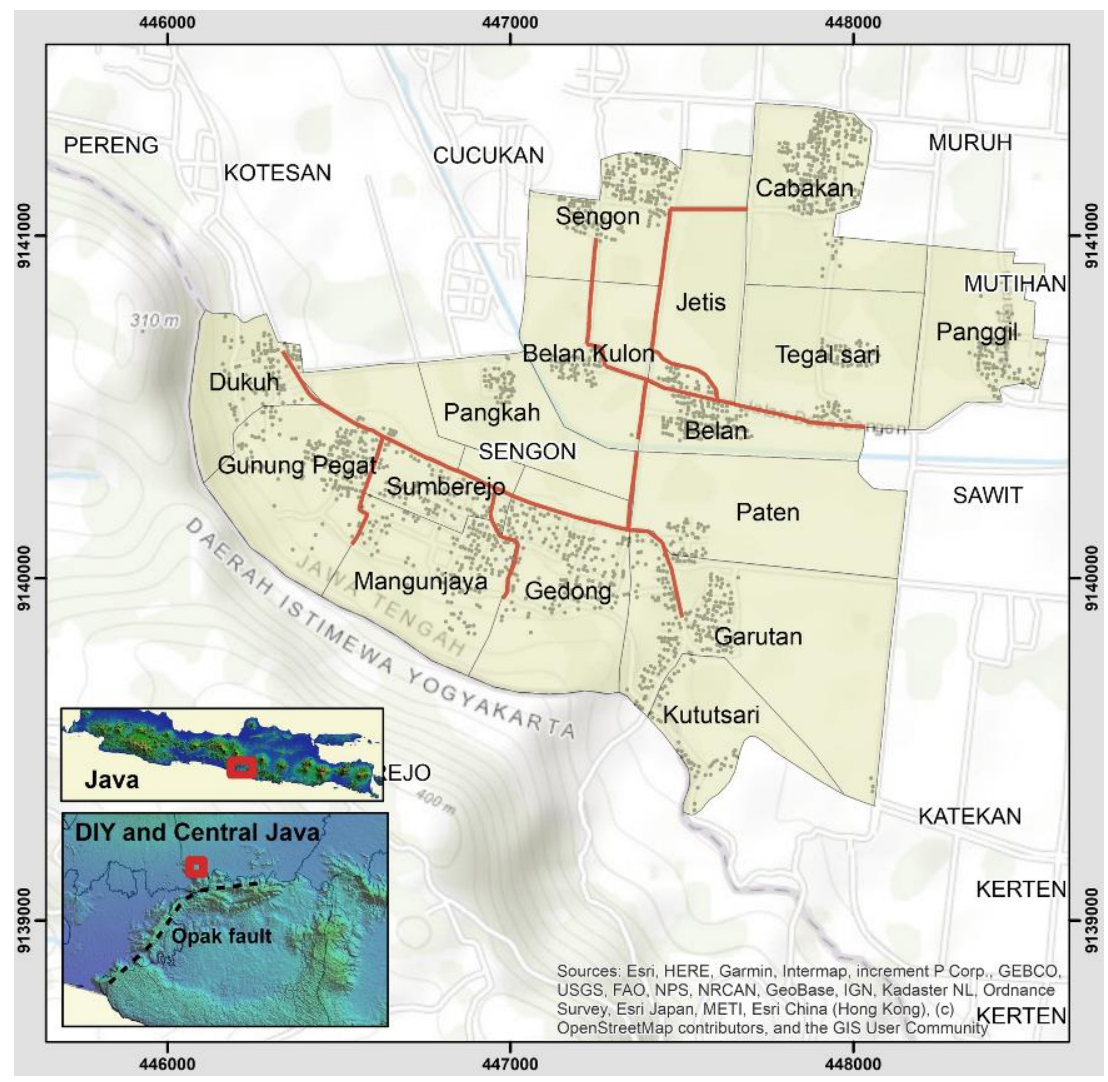

Gambar 3. Peta persebaran bangunan Desa Sengon

Hasil coupling antara kepadatan bangunan dengan kepadatan dan jumlah penduduk dilakukan untuk mengetahui tingkat kerentanan fisik setiap dusun. Terdapat 3 dusun yaitu Dusun Cabakan, Sengon, dan Gedong yang memiliki jumlah penduduk cukup besar dibandingkan dengan dusun lainnya. Secara umum, terdapat korelasi positif antara tingkat kepadatan bangunan dengan jumlah penduduk pada setiap dusun, hanya saja terdapat 3 dusun yang memiliki tingkat korelasi negative yaitu Dusun Sambirejo, Belan, dan Dukuh, Sementara itu, Dusun Cabakan dan Dusun Sengon merupakan dua dusun yang memiliki tingkat kepadatan bangunan tinggi dan jumlah penduduk tinggi (Gambar 4). Hal ini menunjukkan bahwa kedua dusun tersebut memiliki tingkat kerentanan fisik yang lebih tinggi dibandingkan dengan dusun lainnya. 


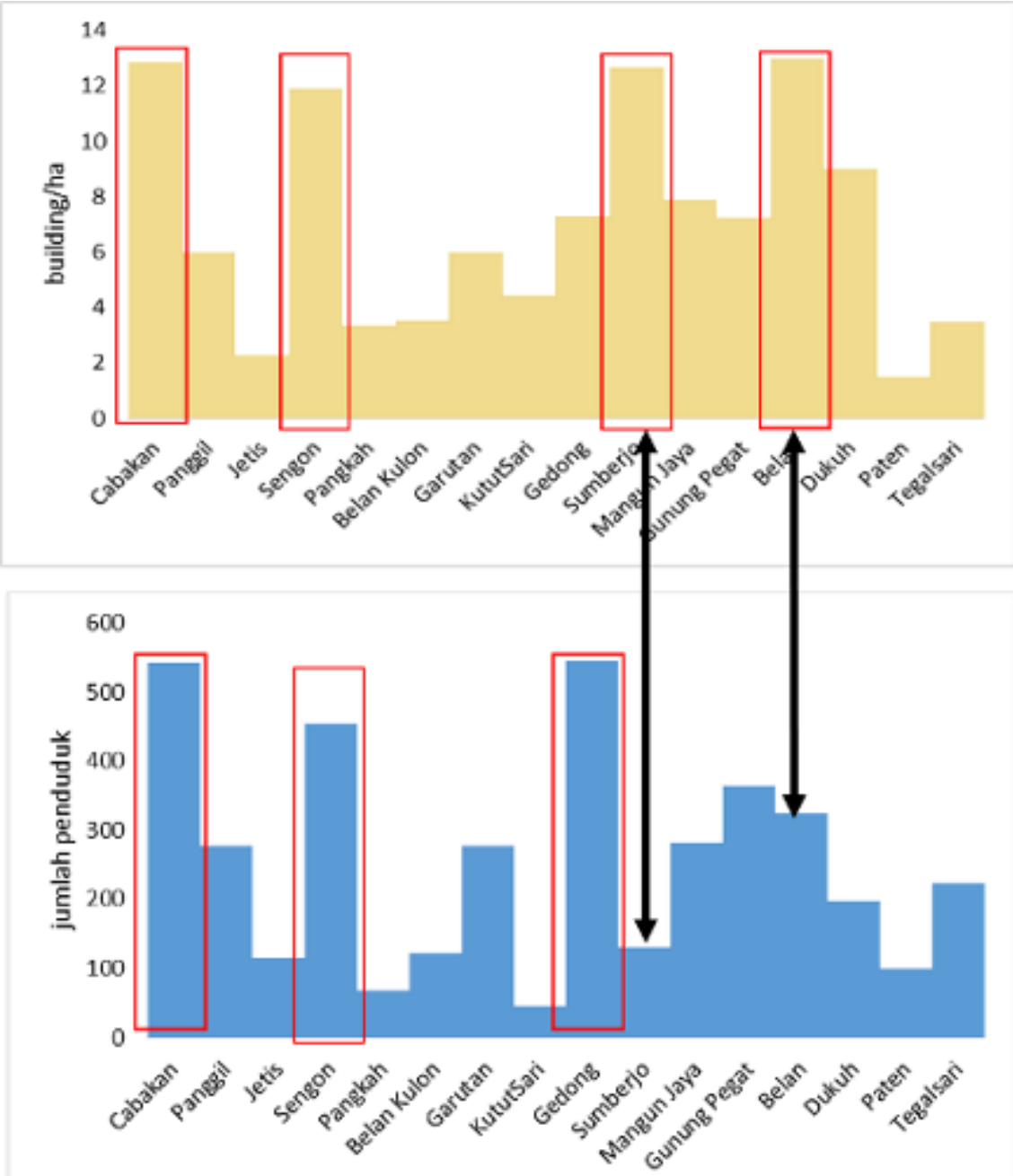

Gambar 4. Hasil coupling tingkat kepadatan bangunan dengan jumlah penduduk

Sampai saat ini, Desa Sengon masih belum memiliki dokumen resmi pengurangan risiko bencana gempa bumi. Berdasarkan hasil analisis diatas, setidaknya terdapat beberapa upaya yang dapat dilakukan untuk pengurangan kerentanan secara fisik di Desa Sengon. Desain rumah menjadi sangat penting dalam upaya penanggulangan gempa bumi. Rumah dengan struktur yang paling kuat dan paling tidak rentan adalah bangunan dari beton/batu bata yang dilengkapi dengan kolom, sedangkan yang paling rentan adalah dari kayu (Aulady dan Fujimi, 2019). Selain itu adanya tiga dusun yang tidak berkorelasi positif lebih disebabkan oleh adanya rumah yang dihuni oleh lebih dari 2-3 kepala keluarga (KK). Oleh sebab itu untuk mengurangi kerentanannya dapat dilakukan upaya desain rumah yang ramah untuk evakuasi dini secara mandiri. Adanya jalur evakuasi yang masih terbatas juga dapat diatasi dengan penambahan khususnya pada wilayah yang padat, seperti di Cabakan, Sengon, Sumberejo, dan Belan.

\section{SIMPULAN}

Terdapat 3 kesimpulan dalam penelitian ini, yaitu (1) Jumlah kepadatan bangunan di Desa Sengon paling tinggi ada di Dusun Cabakan dan Dusun Belan; (2) Kepadatan bangunan dengan jumlah penduduk di Desa Sengon sebagian besar memiliki korelasi yang positif, terdapat 3 dusun yang memiliki korelasi negatif diantaranya Dusun Sumberejo, Belan, dan Dukuh. Hal ini dipengauhi oleh jumlah KK 
atau orang yang tinggal dalam suatu bangunan; serta (3) Upaya pengurangan kerentanan fisik yang dapat dilakukan di Desa Sengon antara lain: (i) mendesain rumah yang ramah dan tahan gempa bumi khususnya bangunan yang dihuni lebih dari 3 kepala keluarga; (ii) menambah ruang terbuka dan jalur evakuasi pada wilayah yang padat bangunan.

\section{DAFTAR PUSTAKA}

Aulady, M.F.N. \& Fujimi, T., 2019, 'Earthquake loss estimation of residential buildings in Bantul regency, Indonesia', Jàmbá: Journal of Disaster Risk Studies 11(1), a756. https://doi.org/10.4102/jamba.v11i1.756

Bayong, T.H.K. (2006). Ilmu Kebumian dan Antariksa. Bandung: PT. Remaja Rosdakarya - UPI.

Desa Sengon (2018). Pofil Desa Sengon. Monogaf Desa. Pemeintah Desa Sengon.

Irajifar, L., Alizadeh T., Sipe N. 2016. The impact of urban form on disaster resiliency: A case study of Brisbane and Ipswich, Australia. International Journal of Disaster Resilience in the Built Environment 7(3). DOI: 10.1108/IJDRBE-10-2014-0074

Mardiatno, D., Faida, L R W., Kusumasari, B., Handayani, T., Susanto, D., Malawani, M N., Erlangga, R I. (2020). Initiative evacuation routes for earthquake hazard in the active Opak fault (Sengon Village, Klaten, Central Java). The 3rd Environmental Resources Management in Global Region.

Ningthoujam, M. C and Radhikesh P. N. (2018). A GIS System Integrated with Earthquake Vulnerability Assessment of RC Building. Structures. 15 (2018), 329-340.

PSBA (2008). Kegiatan Pengurangan Risiko Bencana Alam dan Tsunami Wilayah Pantai Selatan Jawa. Yogyakarta: Laporan Penelitian. Kerjasama antara PSBA UGM dengan Departemen Sosial RI. 